\title{
Ciprofloxacin and levofloxacin adversely affect male infertility indicated by pharmacological, andrological and pathological evidence
}

\author{
Haitham M. Mokhimar¹, Mohamed M. Kandiel², Aziza A. Amin³, \\ Hozaifa K. Elsawah ${ }^{1}$, AbuBakr M. El Mahmoudy ${ }^{1 *}$
}

${ }^{1}$ Department of Pharmacology, ${ }^{2}$ Department of Theriogenology, ${ }^{3}$ Department of Pathology, Benha University Faculty of Veterinary Medicine, Moshtohor, Qalyoubia, Egypt

Received: 20 November 2019

Accepted: 03 Janaury 2020

*Correspondence:

Dr. AbuBakr M. El Mahmoudy,

Email: a.elmahmoudy@fvtm.bu.edu.eg

Copyright: (c) the author(s), publisher and licensee Medip Academy. This is an open-access article distributed under the terms of the Creative Commons Attribution Non-Commercial License, which permits unrestricted non-commercial use, distribution, and reproduction in any medium, provided the original work is properly cited.

\begin{abstract}
Background: Drug-induced reproductive organs toxicities is an important aetiology in investigation of male infertility. The aim is to study levofloxacin effect on male reproductive system in comparison to ciprofloxacin.

Methods: Twenty-five male wister rats weighted $230 \pm 20 \mathrm{gm}$ and aged 8 weeks were randomly divided into five groups of five. The first group received ciprofloxacin with dose $78.23 \mathrm{mg} / \mathrm{kg} / \mathrm{day}$ in 2 doses (therapeutic dose). The second group received the double dose of the first group ciprofloxacin. The third group received levofloxacin with dose $39.11 \mathrm{mg} / \mathrm{kg} /$ day once daily (OD) (therapeutic dose). The Fourth group received the double dose of the third group levofloxacin. However, the fifth group served as a control and received normal saline with carboxymethylcellulose OD. All treatments were administered orally for 14 days. On the $15^{\text {th }}$ day, blood samples and reproductive organs were obtained from all rats. Testicular tissues were prepared for genetic testing and chemical and microscopical examination.

Results: Ciprofloxacin and levofloxacin negatively altered reproductive organ weights, sperm parameters and serum follicle stimulating hormone $(\mathrm{FSH})$ and luteinizing hormone $(\mathrm{LH})$ level $(\mathrm{p}<0.05)$. Additionally, serum testosterone level was significantly deceased in ciprofloxacin-treated group (the double dose) $(\mathrm{p}<0.05)$ relative to control. The difference between ciprofloxacin and levofloxacin was significant in seminal vesicle weight and serum LH and FSH level $(\mathrm{p}<0.05)$. Testicular histopathological changes were also found with the two drugs with different degrees. Effects of levofloxacin and ciprofloxacin were dose-dependent.

Conclusions: Both ciprofloxacin and levofloxacin adversely affect andrological function that should be monitored and controlled during application of these drugs.
\end{abstract}

Keywords: Ciprofloxacin, Levofloxacin, Oxidative, Testis, Sperm, Reproduction, Fertility

\section{INTRODUCTION}

Ciprofloxacin is a second-generation fluroquinolone antibiotic which is the most potent quinolone against Pseudomonas aeruginosa and it has stronger activity against Gram negative bacteria compared with Gram positive. ${ }^{1,2}$ Ciprofloxacin is commonly prescribed for urinary tract infection, orchitis and prostatitis, although bacterial resistance is increasing and gonadotoxicity was reported in human..$^{3-7}$ Levofloxacin is a third generation fluroquinolone antibiotics that has more activity toward Gram positive bacteria. ${ }^{1}$ It is commonly used in respiratory tract infection, urinary tract infection, prostatitis and orchitis. ${ }^{8-12}$

Ciprofloxacin and levofloxacin are lower in side effects compared with ofloxacin specially CNS effects. ${ }^{13}$ However, levofloxacin has more QTc prolongation effect 
on the heart and less effect on hepatic cytochrome enzymes compared with ciprofloxacin. ${ }^{14,15}$ Additionally, levofloxacin has higher oral bioavailability that reached $100 \%$ when compared with ciprofloxacin which equal $69 \% .{ }^{16,17}$ On the contrary to ciprofloxacin, human studies regarding levofloxacin effect on male reproductive system are scarce. However, animal studies are conflicting; some found it was safe and others found it wasn't. ${ }^{18-20}$ Direct comparison between ciprofloxacin and levofloxacin regarding their effects on male reproductive system histopathology, physiology and biochemistry is required to address the relative risk of both drugs on male fertility.

Therefore, the aim of the present study is to asses and evaluate the possible side effects of ciprofloxacin and levofloxacin on testicular function. The aim of the study was effect of ciprofloxacin and levofloxacin on reproductive organs weight (testis, epididymis, prostate and seminal vesicles), effect of ciprofloxacin and levofloxacin on sperm parameters (morphology, motility, mutation), effect of ciprofloxacin and levofloxacin on reproductive hormones (gonadotropins and testosterone) and effect of ciprofloxacin and levofloxacin on histological structure of testis.

\section{METHODS}

\section{Drug preparation}

Ciprofloxacin was purchased as a generic pharmaceutical preparation Serviflox ${ }^{\circledR}$ with concentration $750 \mathrm{mg}$ of ciprofloxacin in one tablet manufactured by Novartis pharma-Cairo, under license of Sandoz GmbH- Australia. The tablets were crushed and diluted with carboxymethylcellulose (CMC) in normal saline (NS) to a final volume $1 \mathrm{ml}$ per one rat. levofloxacin was purchased as a brand pharmaceutical preparation Tavanic $\AA$ with concentration $500 \mathrm{mg}$ of levofloxacin in one tablet produced by: Sanofi-Aventis Egypt SAE. Under license of: Sanofi-Aventis, Germany. The tablets were crushed and diluted with CMC in NS to a final volume $1 \mathrm{ml}$ per one rat. Ciprofloxacin and levofloxacin were administered orally with 18-gauge soft gavage tubes.

\section{Animals}

Twenty-five adult Wistar albino male rats were 8 weeks old and weighting $230 \pm 20 \mathrm{~g}$. They were obtained from animal house of Faculty of Veterinary Medicine, Benha University. Male rats were housed in normal room temperature with humidity (40-60\%) and $12 \mathrm{~h} / 12 \mathrm{~h}$ light or dark cycle prior to use in experimental protocols. The animals were fed laboratory formula and tap water ad libitum.

\section{Study design}

After two weeks of adaptation to a standard diet, the 25 rats were randomly divided into five groups with five rats in each group. Rats in group 1 and 2 received PO ciprofloxacin in two divided daily doses of 78.23 and $156.46 \mathrm{mg} / \mathrm{kg}$ respectively. Rats in group 3 and 4 received PO levofloxacin OD in daily doses of 39.11 and $78.22 \mathrm{mg} / \mathrm{kg}$ respectively. Group 5 served as control and received PO $1 \mathrm{ml} \mathrm{CMC} \mathrm{in} \mathrm{NS} \mathrm{OD.} \mathrm{All} \mathrm{treatments} \mathrm{were}$ administered for 14 days. On the fifteenth day, the five animals in each group were sacrificed by cervical dislocation under anaesthesia after blood sampling. Immediately after dissection, testis, epididymis, prostate, and seminal vesicle were removed and weighted (absolute and relative to body weight). Relative organ weight was expressed as organ weight (mg) or body weight. The experiment was carried out in the Departments of Pharmacology and Theriogenology, Faculty of Veterinary Medicine, Benha University.

\section{Blood sample collection}

Blood samples were collected from the retro-orbital venous plexus located at the medial canthus of the eye by means of heparinized capillary tubes. The collected blood was kept in heparinized test tubes and centrifuged at 1500 $\mathrm{xg}$ for 15 minutes then collected in sterile Eppendorf tubes using automatic pipettes. Plasma samples were kept frozen $\left(-20{ }^{\circ} \mathrm{C}\right)$ till analysis of the following biochemical parameters: testosterone, follicle stimulating hormone (FSH) and luteinizing hormone (LH) using rat ELISA kits (Elabscience®, Taxus, USA).

\section{Tissue sample collection}

About $80 \%$ of the right testis was homogenated with phosphate buffer solution (PBS) at $\mathrm{PH} 7.4$ and centrifuged at $10000 \mathrm{rpm}$ for 10 minutes at $4 \mathrm{C}$. the supernatant was removed and kept at $-20 \mathrm{C}$ till used in analysis. The separated homogenate was used for the estimation of the following parameters: catalase enzyme, superoxide dismutase, malondialdehyde and total antioxidant capacity using universal kits under commercial name of biodiagnostic kits. The rest $20 \%$ of the right testis was used in gene expression analysis. All biochemical analysis was performed in the central lab of the faculty.

\section{Sperm parameter assessment}

Sperms were obtained from the tail of the two epididymis by cutting the epididymis into small pieces in petri dish containing $2 \mathrm{ml}$ of saline $(0.9 \% \mathrm{NaCl})$.

For evaluation of sperm motility, immediately after collection of a semen sample, a small drop was taken with a micropipette and placed on a warm clean glass slide. A cover slip was placed onto the semen drop and the percentage of progressively motile sperms was estimated microscopically at 400x magnification.

For evaluation of sperm morphology and viability, two types of seminal smear slides were obtained from each 
animal. One of them was stained with eosin and nigrosine and the other was fixed in Carnoy's solution then examined with light microscope under magnifications of 400X and 1000X to determine sperm head and tail abnormalities and sperm viability.

For evaluation of sperm count, the epididymal contents extracted in $2 \mathrm{ml}$ normal saline were diluted to $10 \mathrm{ml}$ normal saline and kept for 24 hours to let sperms distribute in the solution. To stain sperms heads to be easily counted, a few drops of eosin $2 \%$ solution were added to the solution before examination. According to the method described previously, the number of sperm in five large squares was multiplied by 5 to obtain sperm count in one chamber that contains 25 large squares (one chamber volume $=100 \mathrm{ml}){ }^{21}$ To obtain sperm count in 1 $\mathrm{ml}$, the number was multiplied by 10000 . Because we diluted semen in $10 \mathrm{ml}$ and used two epididymis, the number was multiplied by 10 and divided by 2 as the following:

Number of sperms per $1 \mathrm{ml}=$

No. of sperms in 5 large squares $\times 5 \times 100000$ 2

\section{Histopathology of the testis}

The left testis was fixed in $10 \%$ formalin and embedded in paraffin. Five-micron thick sections were prepared and stained with hematoxylin and eosin (H\&E). The specimens were examined under Olympus or $3 \mathrm{H}$ light microscope under power of $200 \mathrm{X}$ and $400 \mathrm{X}$. the examination was carried out in the department of pathology of the faculty.

\section{Statistical analysis}

Statistical analysis was performed by using GraphPad Prism 8.0.2 software. Numerical data in this study were expressed as mean \pm standard deviation $(\mathrm{M} \pm \mathrm{SD})$ and categorical data as percentages. Analysis of variance (ANOVA) and a post hoc Tukey test were used. The difference between groups was defined to be statistically significant when a $\mathrm{p}$ value $\leq 0.05$.

\section{Ethics statement}

This study was carried out in strict accordance with the recommendations in the Guide for the Care and Use of Laboratory Animals of the National Institutes of Health 8th edition and adhered to principles published by International Council for Laboratory Animal Science (ICLAS) and those of Benha University Animal Care and Use Committee.

\section{RESULTS}

\section{Body and reproductive organ weights}

After 14 days of treatment, weights of the total body and ventral prostate didn't differ significantly among groups ( $p>0.05)$. Weights of testis, epididymis and seminal vesicle were significantly lower in animals treated with ciprofloxacin and levofloxacin relative to control $(\mathrm{p}<0.05)$. A significant dose dependent effect was observed with testis and epididymis weights in all treated groups $(\mathrm{p}<0.05)$ and seminal vesicle in levofloxacintreated groups $(\mathrm{p}<0.05)$. A significant difference between the two antibiotics was seen with seminal vesicle at the therapeutic dose level $(\mathrm{p}<0.05)$ (Table 1).

Table 1: Total body weight, absolute and relative reproductive organ weights of male rats after administration of ciprofloxacin and levofloxacin with therapeutic and double dose for $\mathbf{1 4}$ days compared with control.

\begin{tabular}{|c|c|c|c|c|c|}
\hline & Control & \multicolumn{2}{|c|}{ Ciprofloxacin (mg/kg) } & \multicolumn{2}{|c|}{ Levofloxacin (mg/kg) } \\
\hline Weight & & 78.23 & 156.46 & 39.11 & 78.22 \\
\hline Total body weight (g) & $274 \pm 2.9$ & $266.4 \pm 3.1$ & $273 \pm 2.7$ & $270.2 \pm 3.2$ & $276 \pm 3.3$ \\
\hline Testis (g) & $1.522 \pm .032$ & $1.098 \pm 0.042 *$ & $0.87 \pm 0.01 *$ & $1.2 \pm 0.041 *$ & $0.83 \pm 0.03 *$ \\
\hline Epididymis (mg) & $556 \pm 16$ & $429 \pm 13 *$ & $383 \pm 8^{*}$ & $455 \pm 9.5^{*}$ & $382 \pm 7.4 *$ \\
\hline Seminal vesicle (mg) & $572 \pm 14$ & $427 \pm 11.7 *$ & $389 \pm 18 *$ & $501 \pm 23^{*}$ & $404 \pm 11.6^{*}$ \\
\hline Ventral prostate (mg) & $486 \pm 18$ & $508 \pm 26.3$ & $464 \pm 12$ & $490 \pm 22.1$ & $496 \pm 24.1$ \\
\hline Relative (R) testis (mg) & $554 \pm 11.5$ & $412 \pm 13.3^{*}$ & $321 \pm 7.8^{*}$ & $444 \pm 19.2 *$ & $302 \pm 11.1^{*}$ \\
\hline R epididymis (mg) & $202.2 \pm 4.5$ & $161.2 \pm 6.1^{*}$ & $140.3 \pm 3.2 *$ & $168.6 \pm 4.6^{*}$ & $138.5 \pm 3.6^{*}$ \\
\hline R seminal vesicle (mg) & $208.7 \pm 7.3$ & $160 \pm 4.6^{*}$ & $144.7 \pm 8.6^{*}$ & $182.3 \pm 8.6$ & $156.8 \pm 8.7 *$ \\
\hline$R$ ventral prostate (mg) & $177.13 \pm 8.3$ & $190.6 \pm 9.05$ & $170 \pm 4$ & $181.6 \pm 9.4$ & $177.13 \pm 8.3$ \\
\hline
\end{tabular}

Values expressed as mean \pm SE of 5 observations, *: significant difference at $p<0.05$ compared with control. One-way ANOVA and post hoc Tukey test were used.

\section{Sperm parameters}

Administration of therapeutic and double dose of both ciprofloxacin and levofloxacin significantly decreased sperm count and progressive motility relative to control $(\mathrm{p}<0.05)$ in a non-significant dose dependent manner
( $>0.05$ ) with nonsignificant differences between the two drugs at the two dose levels ( $>0.05)$ except for levofloxacin with the double dose that showed higher effect on sperm motility compared with the therapeutic dose $(p<0.05)$. Viability and head normality were significantly decreased with the double dose of 
ciprofloxacin and the two doses level of levofloxacin relative to control $(\mathrm{p}<0.05)$ with nonsignificant difference between the antibiotics at the two doses level ( $p>0.05)$. Tail abnormalities were seen with higher significant percentages in the treated groups compared to control $(\mathrm{p}<0.05)$ with nonsignificant dose related effect and significant differences between the two drugs at the two dose levels $(\mathrm{p}<0.05)$ (Table 2).

Table 2: Sperms count, motility, viability and morphology of male rats after administration of ciprofloxacin and levofloxacin with therapeutic and double dose for 14 days compared with control.

\begin{tabular}{|llllll|}
\hline Sperm parameters & Control & \multicolumn{2}{l}{ Ciprofloxacin $(\mathrm{mg} / \mathrm{kg})$} & \multicolumn{2}{l|}{ Levofloxacin (mg/kg) } \\
\hline Sperm count $\left(\mathbf{1 0}^{\wedge} \mathbf{6} / \mathbf{m l}\right)$ & $29.45 \pm 0.72$ & $18.35 \pm 1.05^{*}$ & $16.95 \pm 0.6^{*}$ & $17 \pm 0.9^{*}$ & $16.5 \pm 1.4^{*}$ \\
\hline Progressive motility\% & $73 \pm 4.2$ & $34 \pm 3.2^{*}$ & $23 \pm 2.2^{*}$ & $42 \pm 3.6^{*}$ & $23 \pm 2.2^{*}$ \\
\hline Viability\% & $75 \pm 1.7$ & $70 \pm 1.6$ & $55 \pm 3.9^{*}$ & $60 \pm 1.7^{*}$ & $56 \pm 3.3^{*}$ \\
\hline Head abnormality\% & $3 \pm 0.6$ & $6.4 \pm 1.7$ & $9 \pm 2.1^{*}$ & $17 \pm 1.03^{*}$ & $17 \pm 1.05^{*}$ \\
\hline Tail abnormality\% & $20.6 \pm 2.6$ & $71.6 \pm 3.6^{*}$ & $76 \pm 2.5^{*}$ & $55.8 \pm 1.8^{*}$ & $65.8 \pm 1.7^{*}$ \\
\hline
\end{tabular}

Values expressed as mean \pm SE of 5 observations, *: significant difference at $\mathrm{p}<0.05$ compared with control. One-way ANOVA and post hoc Tukey test were used.

Table 3: Plasma hormones level of male rats after administration of ciprofloxacin and levofloxacin with therapeutic and double dose for 14 days compared with control.

\begin{tabular}{|llllll|}
\hline & Control & \multicolumn{2}{l}{ Ciprofloxacin $(\mathbf{m g} / \mathrm{kg})$} & \multicolumn{3}{l|}{ Levofloxacin $(\mathrm{mg} / \mathrm{kg})$} \\
\hline Testosterone $(\mathbf{n g} / \mathbf{m l})$ & & 78.23 & 156.46 & 39.11 & $78.22 \mathrm{mg} / \mathrm{kg}$ \\
\hline FSH $(\mathbf{n g} / \mathbf{m l})$ & $0.954 \pm 0.07$ & $0.89 \pm 0.07$ & $0.69 \pm 0.06^{*}$ & $0.99 \pm 0.08$ & $0.77 \pm 0.018$ \\
\hline LH $(\mathbf{m I U} / \mathbf{m l})$ & $1.23 \pm 0.05$ & $2.14 \pm 0.1^{*}$ & $4.4 \pm 0.06^{*}$ & $2.4 \pm 0.05^{*}$ & $2.9 \pm 0.06^{*}$ \\
\hline
\end{tabular}

Values expressed as mean \pm SE of 5 observations, *:significant difference at $\mathrm{p}<0.05$ compared with control. One-way ANOVA and post hoc Tukey test were used.

\section{Testosterone, FSH and $\mathrm{LH}$}

Only double dose ciprofloxacin significantly reduced testosterone level $(\mathrm{p}<0.05)$. On the other hand, the two doses of each drug significantly increased $\mathrm{FSH}$ and $\mathrm{LH}$ levels relative to control $(\mathrm{p}<0.05)$. A significant dose dependent effect was seen with FSH and $\mathrm{LH}$ in all treated groups $(p<0.05)$. A significant difference was found between the two drugs in FSH level with all doses $(\mathrm{p}<0.05)$ and LH with the double doses only $(\mathrm{p}<0.05)$. (Table 3).

\section{Histopathological findings}

The testes of the treated rats with therapeutic dose ciprofloxacin for 2 weeks revealed congestion of the subcapsular and interstitial blood vessels. Increase in the thickness of tunica albuginea with numerous degrees of degeneration of the lining epithelial cells of most seminiferous tubules was detected (Figure 1a) and occasionally accompanied by reduced spermatogenesis and absence of spermatozoa in the lumen of these degenerated tubules. Meanwhile, swollen, pale and vacuolated cytoplasm of the lining epithelium of some seminiferous tubules with accumulation of necrotic eosinophilic debris in the lumen of some seminiferous tubules was seen as well as incomplete spermatogenesis and absence of spermatozoa in the lumen of these degenerated tubules (Figure 1b). The testicular interstitium was expanded by homogenous eosinophilic material (edema) admixed with interstitial cells (Leydig cells) and few mononuclear leukocytic cellular infiltration (Figure 1c). Multifocally, the lining epithelial cells of some seminiferous tubules exhibited degeneration characterized by swollen pale discrete large vacuoles, usually replaced the cytoplasm. Rarely, degenerated tubules showed exfoliated epithelial cells in their lumen (Figure 1).

However, these histopathological changes were more pronounced in rats treated with double dose ciprofloxacin for 2 weeks. The testes of these animals showed marked congestion and thrombosis of the testicular blood vessels with obvious sub-capsular and inter-tubular edema (Figure 1d). The seminiferous tubules were more affected with extensive testicular degeneration of great numbers of seminiferous tubules was observed (Figure 1e). Marked reduction in the number of the germinal epithelium of seminiferous tubules with complete inhibition of spermatogenesis in most tubules. Extensive necrosis of germinal epithelium of seminiferous tubules with stop of spermatogenesis was also detected (Figure 1f). Additionally, dead and hyalinized sperms were demonstrated in the lumen of some seminiferous tubules (Figure 1g). Moreover, destruction of the basement membrane of some seminiferous tubules with distension of its lumen with desquamated germinal cells was also noticed. In the meantime, multiple areas of lytic necrosis of the germinal epithelium of seminiferous tubules that characterized by complete loss of spermatogenic cells in some seminiferous tubules was also demonstrated. 

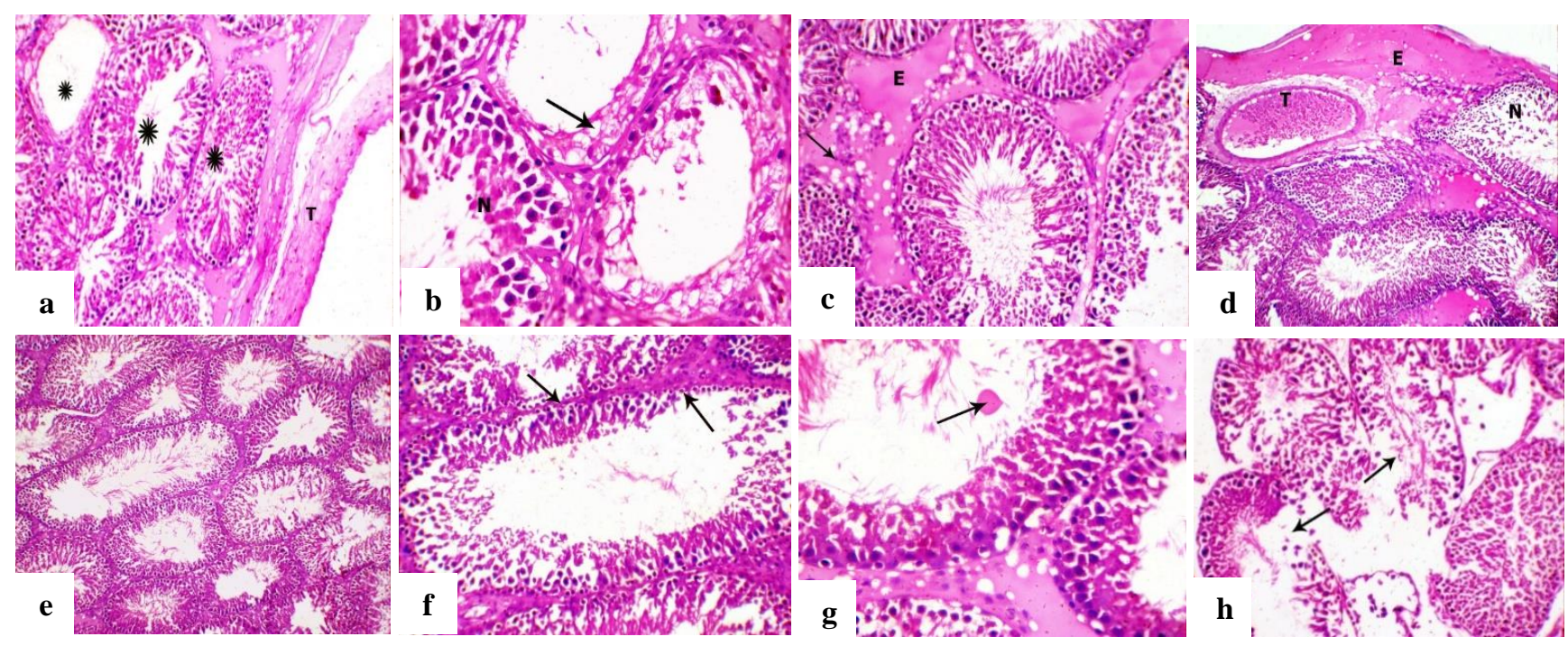

Figure 1: H\&E stained section of testes obtained from rat treated with therapeutic dose ciprofloxacin (a-c) and double dose ciprofloxacin (d-h) for 2 weeks showing (a) increase in the thickness of tunica albuginea (T) with variable degree of degeneration of the lining epithelium of some seminiferous tubules (asterisk, X200), (b) loss of spermatids with severe degenerative changes with vacuolated (arrow) and necrosis $(\mathrm{N})$ of the lining epithelium of some seminiferous tubules (X400), (c) inter-tubular edema (E) admixed with leydig cells and few leukocytic infiltration (arrow, X400), (d) thrombosis of the testicular blood vessels (T) with sub-capsular and inter-tubular edema and necrosis $(\mathrm{N})$ of the lining epithelium of some seminiferous tubules (X400), (e) variable degree of degenerative changes of the lining epithelium of seminiferous tubules (X200), (f) Extensive necrosis of spermatogenic cells of seminiferous tubules with stop of spermatogenesis (arrow, X400), (g) dead and hyalinized sperm in the lumen of some seminiferous tubules (arrow) with inter-tubular edema (X400), (h) destruction of the basement membrane of some seminiferous tubules with complete absence of germinal cells (arrow) and distension of its lumen with desquamated epithelial cells (X200).

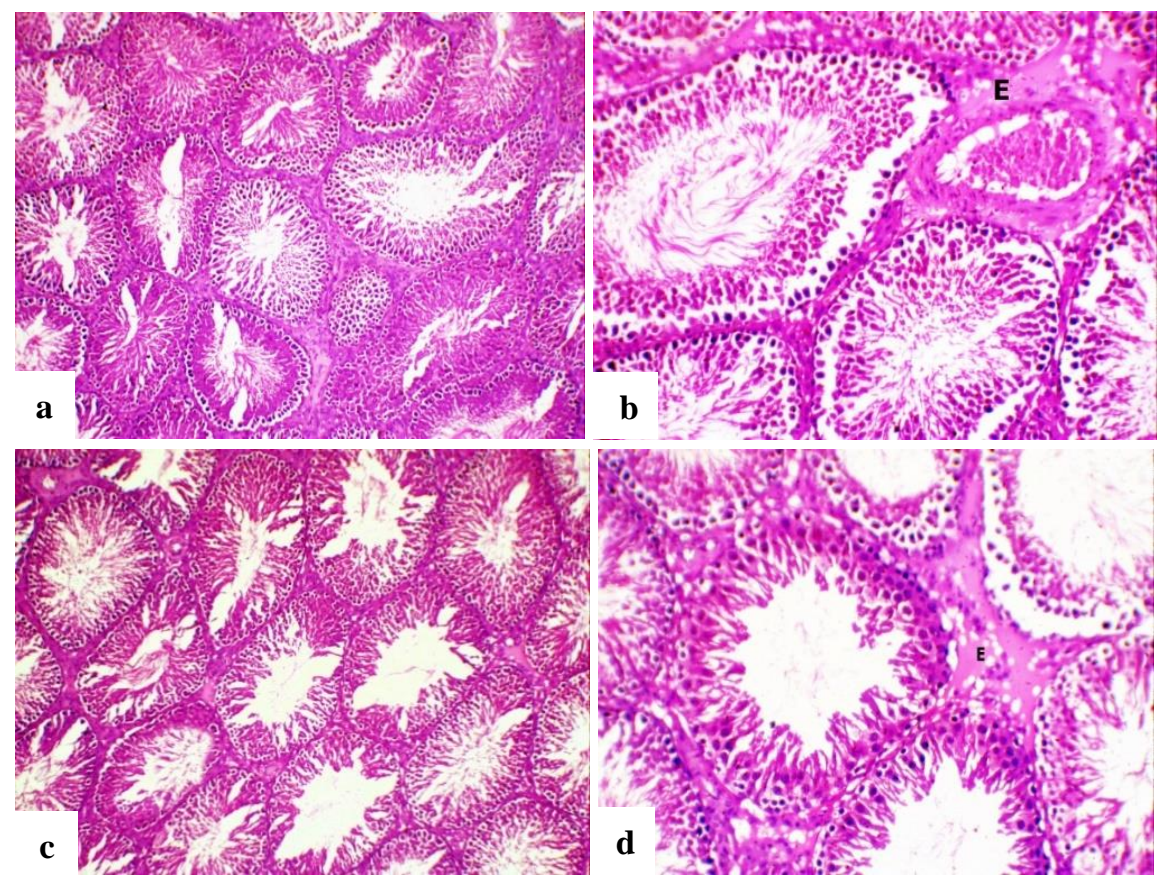

Figure 2: H\&E stained section of testes obtained from rat treated with therapeutic dose levofloxacin (a-b) and double dose levofloxacin (c-d) for 2 weeks showing (a) most of the seminiferous tubules were compact with each

other with normal spermatogenic layers (X100), (b) mild degeneration of the germinal epithelium of some seminiferous tubules with mild inter-tubular edema (E, X200), (c) degeneration of germinal epithelium with incomplete of spermatogenesis (X100), (d) severe degenerative changes with and loss of spermatids and inhibition of spermatogenesis as well as marked inter-tubular edema (E, X200). 
However, the microscopical examination of testes of animals treated for 2 weeks with therapeutic dose of levofloxacin revealed less obvious histopathological changes when compared with the group treated with therapeutic dose ciprofloxacin for the same period. Most of the seminiferous tubules were compact with each other and the spermatogenic layers appeared normal in most examined animals (Figure 2a), consequently, most of the seminiferous tubules restored its normal histological architecture except mild congestion of testicular blood vessels, with mild degeneration of the germinal epithelium of some seminiferous tubules with mild intertubular edema (Figure 2b) and hyperplasia of Leydig cells was demonstrated only in two examined cases.

On the other side, the testes treated with double dose levofloxacin revealed more advanced pathological changes in comparison to the testes treated with therapeutic dose of levofloxacin. Meanwhile, these pathological alterations were less prominent when compared with the testes of animals treated with the double dose ciprofoxacin. The testes of the treated rats revealed congestion of the testicular blood vessels with degeneration of its wall. Multifocally, the lining epithelial cells of large numbers of seminiferous tubules exhibited variable degenerative changes (Figure 2c) characterized by reduction in the number of germ cells and inhibition of spermatogenesis with accumulation of inter-tubular edematous fluid admixed with leydig cells was detected in most investigated rats (Figure 2d).

On the other side, normal histological structure of tunica albuginea, seminiferous tubules and interstitial tissue was detected during the histopathological examination of the testes taken from rats received control. (group 1).

\section{DISCUSSION}

Medications are important aetiology of male infertility and should be investigated carefully when diagnose male infertility. ${ }^{22,23}$ Ciprofloxacin and to a lesser extent, levofloxacin have been studied in rats regarding their effect on male reproductive system. The present study calculated the therapeutic doses based on the average doses of $\mathrm{Kg}$-based dosing that equal 21.5 and 10.71 $\mathrm{mg} / \mathrm{kg} /$ day in ciprofloxacin and levofloxacin respectively and body surface area-based dosing that equal 135 and $67.5 \mathrm{mg} / \mathrm{kg} /$ day in ciprofloxacin and levofloxacin respectively. ${ }^{31}$ So, the therapeutic doses are 78.23 and $39.11 \mathrm{mg} / \mathrm{kg} / \mathrm{day}$ and the double doses are 156.45 and $78.23 \mathrm{mg} / \mathrm{kg} /$ day in ciprofloxacin and levofloxacin respectively that fall in the previous dosing ranges. Different doses and durations were used in the previous reproductive animal studies and it ranged from 12.5 $\mathrm{mg} / \mathrm{kg}$ ciprofloxacin daily for 60 days, $150 \mathrm{mg} / \mathrm{kg}$ for 10 days and $135 \mathrm{mg} / \mathrm{kg}$ for 15 days and 12 weeks to 206 and $412 \mathrm{mg} / \mathrm{kg}$ for 45 days and ranged from $0.03,0.06$ and $0.08 \mathrm{mg} / \mathrm{kg}$ levofloxacin for 60 days to 37.5 and $75 \mathrm{mg} / \mathrm{kg}$ for 14 and 28 days. ${ }^{20,24-30}$ The present study showed that the testis, epididymis and seminal vesicle weight were negatively affected by the ciprofloxacin and levofloxacin with the therapeutic and double doses $(p<0.05)$. Similar findings were observed and it was found that testis, epididymis and seminal vesicle weight were significantly reduced $(\mathrm{p}<0.05)$ after 60 days treatment with ciprofloxacin $12.5 \mathrm{mg} / \mathrm{kg} / \mathrm{day} .{ }^{24}$ Testis weight depends on germ cell content and loss of these cells decreases the testis weight. ${ }^{32}$ Consistent with this, histopathological findings of the present study reported testicular cells loss including germ cells and other cells. In the present study, both levofloxacin and ciprofloxacin significantly impaired sperm parameters $(\mathrm{p}<0.05)$. Previous studies reported that sperm count was decreased after 10 days treatment with $150 \mathrm{mg} / \mathrm{kg}$ ciprofloxacin; sperm motility count and viability were also reduced after 60 days treatment with $12.5 \mathrm{mg} / \mathrm{kg}$ ciprofloxacin and daily sperm production, motility and total sperm count were decreased after 15 days treatment with $135 \mathrm{mg} / \mathrm{kg}$ ciprofloxacin. ${ }^{24,26,27} \mathrm{On}$ the other hand, sperm parameters weren't affected significantly with either 37.5 or $75 \mathrm{mg} / \mathrm{kg}$ levofloxacin for 14 days, but they were significantly reduced after 28 days treatment. $^{20}$ Testosterone is important hormone in maintaining testis weight through maintenance of the spermatogenic process and inhibition of germ cell apoptosis. ${ }^{33}$ However, testosterone was reduced only with double dose ciprofloxacin $(\mathrm{p}<0.05)$ which is similar to the effect of $135 \mathrm{mg} / \mathrm{kg}$ ciprofloxacin after 14 days treatment that significantly reduced serum testosterone. ${ }^{28}$ Testosterone was also reduced after 45 days treatment with 206 and $412 \mathrm{mg} / \mathrm{kg}$ ciprofloxacin $(\mathrm{p}<0.05) .{ }^{29}$ On the other hand, levofloxacin in the present study didn't have a significant effect on serum testosterone $(p>0.05)$. Consistent with our findings, levofloxacin with dose 75 $\mathrm{mg} / \mathrm{kg}$ for 28 days didn't affect testosterone level. ${ }^{20}$ Meanwhile, low doses of levofloxacin with 0.03, 0.06 and $0.08 \mathrm{mg} / \mathrm{kg}$ didn't affect testosterone level, but increased FSH and LH levels. ${ }^{30}$ This study found a significant effect of ciprofloxacin and levofloxacin on FSH and $\mathrm{LH}$ that were increased relative to control $(\mathrm{p}<0.05)$ which is different from the effect of $416 \mathrm{mg} / \mathrm{kg}$ ciprofloxacin that significantly reduced $\mathrm{FSH}$ and $\mathrm{LH}$, but $206 \mathrm{mg} / \mathrm{kg}$ ciprofloxacin didn't have a significant effect. ${ }^{29}$ This discrepancy may be related to different animal ages or species. One possible mechanism of ciprofloxacin and levofloxacin-induced testicular cell damage is oxidative stress where it was found that ciprofloxacin increased testicular oxidative stress and levofloxacin increased oxidative stress in other organs such as plasma. ${ }^{34,35}$ Direct effect of levofloxacin on testicular oxidative stress in comparison with ciprofloxacin will be presented in a separate investigation by our team. It might give some explanations for the small difference between the two drugs regarding their negative effects on male reproductive system. Another possible explanation is the blood-testis barrier; a tight junction between Sertoli cells that protect germ cells from substances penetration and there is a good correlation between lipophilicity of the drug and its permeability through blood-tissue barriers. $^{36,37}$ Levofloxacin is more lipophilic than ciprofloxacin. ${ }^{38}$ So, it is predicted that levofloxacin 
achieved higher testicular concentration relative to blood than ciprofloxacin. The present study showed histopathological alterations in seminiferous tubules and interstitial tissues with ciprofloxacin and to a lesser extent levofloxacin. Similar findings were reported with levofloxacin and ciprofloxacin. ${ }^{24,26,30}$ Finally, human follow up studies are required to keep caution regarding negative effect of ciprofloxacin and levofloxacin on human fertility specially couples seeking for children.

\section{CONCLUSION}

Treatment with either ciprofloxacin or levofloxacin exhibited variable degree of testicular degeneration via induction of histopathological alterations in the seminiferous tubules and interstitial tissues, impaired sperm parameters and affect hormone level. The severity of these changes was dose dependent. Levofloxacin relative to ciprofloxacin is slightly less gonadotoxic but relative to control, levofloxacin retained gonadotoxicity. So, monitoring the patient under therapy is required.

\section{ACKNOWLEDGEMENTS}

We gratefully thank doctors and other workers of the central laboratory of the faculty for their support and help specially Dr. Ibrahim Abdel-Wadoud for carrying out biochemical tests.

\section{Funding: No funding sources}

Conflict of interest: None declared

Ethical approval: Not required

\section{REFERENCES}

1. Kowalski RP, Dhaliwal DK, Karenchak LM, Romanowski EG, Mah FS, Ritterband DC, et al. Gatifloxacin and moxifloxacin: an in vitro susceptibility comparison to levofloxacin, ciprofloxacin, and ofloxacin using bacterial keratitis isolates. Am J Ophthalmol. 2003;136(3):500-5.

2. Walker RC, editor The fluoroquinolones. Mayo Clinic Proceedings; Elsevier. 1999.

3. Krcmery S, Naber K, German Ciprofloxacin U, Group US, Naber K, R Barth M, et al. Ciprofloxacin once versus twice daily in the treatment of complicated urinary tract infections. Int $\mathbf{J}$ Antimicrobial Agents. 1999;11(2):133-8.

4. Humphreys H, Speller D. Acute epididymo-orchitis caused by Pseudomonas aeruginosa and treated with ciprofloxacin. J Infect. 1989;19(3):257-61.

5. Bundrick W, Heron SP, Ray P, Schiff WM, Tennenberg AM, Wiesinger BA, et al. Levofloxacin versus ciprofloxacin in the treatment of chronic bacterial prostatitis: a randomized double-blind multicenter study. Urology. 2003;62(3):537-41.

6. Killgore KM, March KL, Guglielmo BJ. Risk factors for community-acquired ciprofloxacin-resistant Escherichia coli urinary tract infection. Ann Pharmacotherap. 2004;38(7-8):1148-52.
7. Merino G, Carranza-Lira S. Infection and male infertility: effect of different antibiotic regimens on semen quality. Arch Androl. 1995;35(3):209-12.

8. Al-Tawfiq JA, Momattin H, Hinedi K. Empiric antibiotic therapy in the treatment of communityacquired pneumonia in a general hospital in Saudi Arabia. J Global Infect Dis. 2019;11(2):69.

9. Chao Y-S, Farrah K. Fluoroquinolones for the Treatment of Urinary Tract Infection: A Review of Clinical Effectiveness, Cost-Effectiveness, and Guidelines. 2019.

10. Peterson J, Kaul S, Khashab M, Fisher AC, Kahn JB. A double-blind, randomized comparison of levofloxacin $750 \mathrm{mg}$ once-daily for five days with ciprofloxacin 400/500 mg twice-daily for 10 days for the treatment of complicated urinary tract infections and acute pyelonephritis. Urology. 2008;71(1):17-22.

11. Nickel JC, Downey J, Clark J, Casey RW, Pommerville PJ, Barkin J, et al. Levofloxacin for chronic prostatitis/chronic pelvic pain syndrome in men: a randomized placebo-controlled multicenter trial. Urology. 2003;62(4):614-7.

12. Garthwaite MA, Johnson G, Lloyd S, Eardley I. The implementation of European Association of Urology guidelines in the management of acute epididymoorchitis. Ann Royal Coll Surgeons Engl. 2007;89(8):799-803.

13. Ball P. Safety of the new fluoroquinolones compared with ciprofloxacin. J Chemotherap. 2000;12(sup1):811.

14. Farkas A, Woods KL, Ciummo F, Shah A, Sassine J, Olivo Freites C, et al., editors. 1545. Development of a Linear Mixed-Effect Pharmacodynamic Model to Quantify the Effects of Frequently Prescribed Antimicrobials on QT Interval Prolongation in Hospitalized Patients. Open Forum Infectious Diseases; 2019: Oxford University Press US.

15. Podder V, Sadiq NM. Levofloxacin. StatPearls: StatPearls Publishing; 2019.

16. Fish DN, Chow AT. The clinical pharmacokinetics of levofloxacin. Clin Pharmacokinet. 1997;32(2):10119.

17. Drusano G, Standiford H, Plaisance K, Forrest A, Leslie J, Caldwell J. Absolute oral bioavailability of ciprofloxacin. Antimicrobial Agents And Chemotherap. 1986;30(3):444-6.

18. Watanabe T, Fujikawa K, Harada S, Ohura K, Sasaki T, Takayama S. Reproductive toxicity of the new quinolone antibacterial agent levofloxacin in rats and rabbits. Arzneimittel-Forschung. 1992;43(3):374-7.

19. Vicari L, Castiglione R, Salemi M, Vicari B, Mazzarino M, Vicari E. Effect of levofloxacin treatment on semen hyperviscosity in chronic bacterial prostatitis patients. Andrologia. 2016;48(4):380-8.

20. Al-Dujaily S, Abd AH, Al-Saray DA. Effects of Levofloxacin on Male Reproductive System Parameters and Sperm DNA Normality in Rats. J Pharma Sci Re. 2018;10(3):462-6. 
21. Luthfi MJf. A Simple and Practical Method for Rat Epididymal Sperm Count (Rattus norvegicus). Biol Med Natural Product Chem. 2015;4(1):1-3.

22. Semet M, Paci M, Saïas-Magnan J, MetzlerGuillemain C, Boissier R, Lejeune $\mathrm{H}$, et al. The impact of drugs on male fertility: a review. Andrology. 2017;5(4):640-63.

23. Staff A. The Optimal Evaluation of the Infertile Male: AUA Best Practice Statement. 2010.

24. Khaki A. Effect of ciprofloxacin on cauda epididymis sperm quality and apoptosis. J Urmia Univ Med Sci. 2008;19(1):29-35.

25. Arash K, Peirouvi T. Effect of ciprofloxacin on cauda epididymis sperm quality and apoptosis. J Urmia Univ Med Sci. 2008;19(1):29-35.

26. Demir A, Türker P, Önol FF, Sirvanci S, Findik A, Tarcan T. Effect of experimentally induced Escherichia coli epididymo-orchitis and ciprofloxacin treatment on rat spermatogenesis. International journal of urology. 2007;14(3):268-72.

27. Abd-Allah AR, Aly HA, Moustafa AM, Abdel-Aziz A-AH, Hamada FM. Adverse testicular effects of some quinolone members in rats. Pharmacol Res. 2000;41(2):211-9.

28. Iqbal R, Iqbal S, Anjum S. Effect of Quinolones on Serum Testosterone Level in Male Albino Rats. Ann King Edward Medical Univ. 2017;23(1).

29. Zobeiri F, Sadrkhanlou R-A, Salami S, Mardani K. Long-term effect of ciprofloxacin on testicular tissue: evidence for biochemical and histochemical changes. Int J Fertility Sterility. 2013;6(4):294.

30. Ahmadi R, Ahmadifar M, Safarpour E, VahidiEyrisofla N, Darab M, Eini AM, et al. The effects of levofloxacin on testis tissue and spermatogenesis in rat. Cell J (Yakhteh). 2016;18(1):112.
31. Laurence DR, Bacharach AL. Evaluation of drug activities: pharmacometrics: ASPET; 1964.

32. Kerr J. Spontaneous degeneration of germ cells in normal rat testis: assessment of cell types and frequency during the spermatogenic cycle. Reproduction. 1992;95(3):825-30.

33. Dohle G, Smit M, Weber R. Androgens and male fertility. World J Urol. 2003;21(5):341-5.

34. Nashwa A, Kawkab AA, Mouneir SM. The protective effect of ginger and $\mathrm{N}$-acetyl cysteine on ciprofloxacin-induced reproductive toxicity in male rats. J Am Sci. 2011;7(7).

35. Talla V, Veerareddy P. Oxidative stress induced by fluoroquinolones on treatment for complicated urinary tract infections in Indian patients. J Young Pharmacists. 2011;3(4):304-9.

36. Dym M, Fawcett DW. The blood-testis barrier in the rat and the physiological compartmentation of the seminiferous epithelium. Biol Reprod. 1970;3(3):308-26.

37. Tsuji A, Tamai I. Blood-brain barrier function of Pglycoprotein. Advanced Drug Delivery Rev. 1997;25(2-3):287-98.

38. Blokhina SV, Sharapova AV, Ol'khovich MV, Volkova TV, Perlovich GL. Solubility, lipophilicity and membrane permeability of some fluoroquinolone antimicrobials. Eur J Pharma Sci. 2016;93:29-37.

Cite this article as: Mokhimar HM, Kandiel MM, Amin AA, Elsawah HK, El Mahmoudy AM. Ciprofloxacin and levofloxacin adversely affect male infertility indicated by pharmacological, andrological and pathological evidence. Int $\mathbf{J}$ Basic Clin Pharmacol 2020;9:353-60. 